\title{
Thoracoscopic sympathetic block to predict compensatory hyperhidrosis in primary hyperhidrosis
}

\author{
June Lee ${ }^{1}$, Jin Yong Jeong ${ }^{1}$, Jong Hui Suh ${ }^{1 \wedge}$, Chan Beom Park ${ }^{1}$, Hana Kwoun ${ }^{2} \wedge$, Soo Seog Park ${ }^{2} \wedge$ \\ ${ }^{1}$ Department of Thoracic and Cardiovascular Surgery, Incheon St. Mary's Hospital, College of Medicine, The Catholic University of Korea, Seoul, \\ Republic of Korea; ${ }^{2}$ Department of Anesthesiology, Incheon St. Mary's Hospital, College of Medicine, The Catholic University of Korea, Seoul, \\ Republic of Korea \\ Contributions: (I) Conception and design: J Lee, JY Jeong; (II) Administrative support: JY Jeong; (III) Provision of study materials or patients: J Lee, \\ JY Jeong; (IV) Collection and assembly of data: J Lee, JY Jeong, H Kwoun, SS Park; (V) Data analysis and interpretation: J Lee, JY Jeong, JH Suh, \\ CB Park; (VI) Manuscript writing: All authors; (VII) Final approval of manuscript: All authors. \\ Correspondence to: Dr. Jin Yong Jeong, MD, PhD. Department of Thoracic and Cardiovascular Surgery, Incheon St. Mary's Hospital, College of \\ Medicine, The Catholic University of Korea, 56 Dongsu-ro, Bupyeong-gu, Incheon 21431, Republic of Korea. Email: jeong74@catholic.ac.kr.
}

\begin{abstract}
Background: Compensatory hyperhidrosis is the main cause of patients' dissatisfaction following sympathectomy for primary hyperhidrosis. Therefore, thoracoscopic sympathetic nerve block before sympathectomy can be used to predict compensatory hyperhidrosis after sympathectomy. The objective of this study is to review our recent experience with the nerve block procedure, describing efficacy, safety and validity.

Methods: We retrospectively reviewed the medical records of 107 patients who underwent thoracoscopic sympathetic nerve block with a local anesthetic for primary palmar and craniofacial hyperhidrosis using a 2-mm needlescope from March 2017 to November 2019. A week later, the patients were interviewed, and a decision made as to whether to proceed with sympathectomy. We analyzed the perioperative data of patients who underwent the predictive procedure either followed, or not followed, by sympathectomy.

Results: Primary hyperhidrosis was relieved in all patients by the predictive procedure without severe complications. Compensatory hyperhidrosis happened to 32 patients (29.9\%). Seventy-eight patients (72.9\%) decided to undergo sympathectomy (group A) and 29 patients (27.1\%) refused the sympathectomy (group B). Group B tended to have higher average body mass index $\left(24.5\right.$ versus $\left.23.2 \mathrm{~kg} / \mathrm{m}^{2}, \mathrm{P}=0.082\right)$ and compensatory hyperhidrosis rate after predictive procedure $(37.9 \%$ versus $26.9 \%, \mathrm{P}=0.269)$ compared to group A. The compensatory hyperhidrosis rate after sympathectomy in group A was $76.9 \%$. The effective duration of sympathetic block was significantly longer in group A than in group B (33.5 versus 13.9 hours, $\mathrm{P}=0.001$ ). The predictive procedure had $94.4 \%$ specificity and $33.3 \%$ sensitivity for prediction of compensatory hyperhidrosis.

Conclusions: Thoracoscopic sympathetic block may be safe and feasible as a procedure for predicting compensatory hyperhidrosis after sympathectomy, and beneficially, it allows the patients to experience the effect of sympathectomy on primary hyperhidrosis and occurrence of compensatory hyperhidrosis. However, a longer effective duration of sympathetic block is needed to help patients to decide whether to proceed with the surgery.
\end{abstract}

Keywords: Hyperhidrosis; video-assisted thoracoscopic surgery (VATS); sympathectomy; compensatory hyperhidrosis $(\mathrm{CH})$; sympathetic block

Submitted Feb 03, 2021. Accepted for publication Apr 29, 2021.

doi: $10.21037 /$ jtd-21-229

View this article at: http://dx.doi.org/10.21037/jtd-21-229

\footnotetext{
^ ORCID: June Lee, 0000-0002-3889-069X; Jin Yong Jeong, 0000-0002-2079-0279; Jong Hui Suh, 0000-0003-2863-9239; Hana Kwoun, 0000-0001-8024-1450; Soo Seog Park, 0000-0001-5011-4346.
} 


\section{Introduction}

Thoracoscopic sympathectomy is the preferred treatment for severe primary hyperhidrosis $(\mathrm{PH})(1,2)$. Compensatory hyperhidrosis $(\mathrm{CH})$ is one of the severe complications that can occur after thoracoscopic sympathectomy and happens in $55-92 \%$ of patients (3-6). There have been several strategies to reduce $\mathrm{CH}$, including limited level sympathectomy $(7,8)$ or lower level sympathectomy $(9,10)$. Postsympathectomy $\mathrm{CH}$ has been the major cause of dissatisfaction for patients $(7,11)$.

Even though there have been reports on attempts to reverse the effect of sympathetic surgery by clip removal, reversibility of $\mathrm{CH}$ was seen in only half the patients (12). A report of sympathetic nerve reconstruction after sympathectomy showed similar rates of $\mathrm{CH}$ improvement (13). A temporary thoracoscopic sympathetic block was performed as a means to determine postsympathectomy $\mathrm{CH}$ (14). We started thoracoscopic sympathetic nerve block under local anesthesia, which we have labelled a predictive procedure, to predict the likelihood of $\mathrm{CH}$ after sympathectomy since 2009. Based on our initial studies $(15,16)$, we were convinced that our predictive procedure could be helpful to patients in anticipating the occurrence and severity of $\mathrm{CH}$ after sympathectomy.

There are currently very few published studies about the efficacy of this thoracoscopic nerve block. The purpose of this study is to review our recent experience with this predictive procedure, describing efficacy, safety and validity.

We present the following article in accordance with the STROBE reporting checklist (available at http://dx.doi. org/10.21037/jtd-21-229).

\section{Methods}

\section{Patients}

We retrospectively reviewed the medical records of 107 patients with severe primary palmar and craniofacial hyperhidrosis who underwent the thoracoscopic sympathetic nerve block performed by the same surgeon from March 2017 to November 2019. All patients had grade 3 or 4 symptoms on the hyperhidrosis disease scale (17). We excluded $\mathrm{CH}$ or recurrent hyperhidrosis patients who had previous treatments as well as patients who required multilevel sympathetic nerve blocks due to multiple symptom sites with the exception of palmar or craniofacial. We sorted the patients based on the algorithm shown in Figure 1. The study was conducted in accordance with the Declaration of Helsinki (as revised in 2013). The study was approved by the Institutional Review Board (IRB) of our medical institution (IRB approval number: OC20RASI0095). Informed consent was waived due to the retrospective nature of the current study.

\section{Thoracoscopic sympathetic block}

Patients were placed in the prone position with both arms abducted $90^{\circ}$ and with both elbows flexed less than $90^{\circ}$ (Figure 2A). Temperature probes (Skin Temperature Probe D-S18A, Exacon Scientific, Roskild, Denmark) were applied on both palms. Under local anesthesia with $0.5 \%$ lidocaine infiltrated into the fifth intercostal space at the mid-axillary line, a surgical trocar (MiniPort $2 \mathrm{~mm}$, Tyco Healthcare UK Ltd., Gosport, UK) was inserted. After $\mathrm{CO}_{2}$ insufflation into the pleural space, a 2-mm thoracoscope was inserted. Visually confirming with the videoscope, a spinal needle (23 G×89 mm, Hakko Co. Ltd., Chikuma, Japan) was introduced onto the sympathetic nerve just above the parietal pleura through the intercostal space from the patient's back (Figure $2 B$ ). About $10 \mathrm{~mL}$ of a mixture (ropivacaine $37.5 \mathrm{mg}$, dexamethasone $5 \mathrm{mg}$ and $0.05 \mathrm{~mL}$ of $0.1 \%$ epinephrine solution) was injected through the spinal needle around both target sympathetic chains and ganglia. After confirming the temperature of the hands started to elevate, we sucked out the air through the trocar while the patient in Valsalva maneuver and removed the trocar. Patients were discharged from the hospital on the day of operation without severe complications requiring chest tube after the procedure.

\section{Thoracoscopic sympathectomy}

Under endotracheal general anesthesia, patients were placed in the supine position with both arms abducted $90^{\circ}$ and with the temperature probes applied on both palms. After $\mathrm{CO} 2$ insufflation into the pleural space through a surgical trocar, a $2-\mathrm{mm}$ thoracoscope was inserted. While confirming surgical field with the videoscope, a 2-mm endoscissors (Scissors $2 \mathrm{~mm}$, Richard Wolf Medical Instruments Co., Vernon Hills, IL, USA) was introduced to cut the target sympathetic chain. After sucking out the air through the trocar it was removed.

\section{Post-procedure and postsympathectomy interview}

A week after the predictive procedures, patients were 


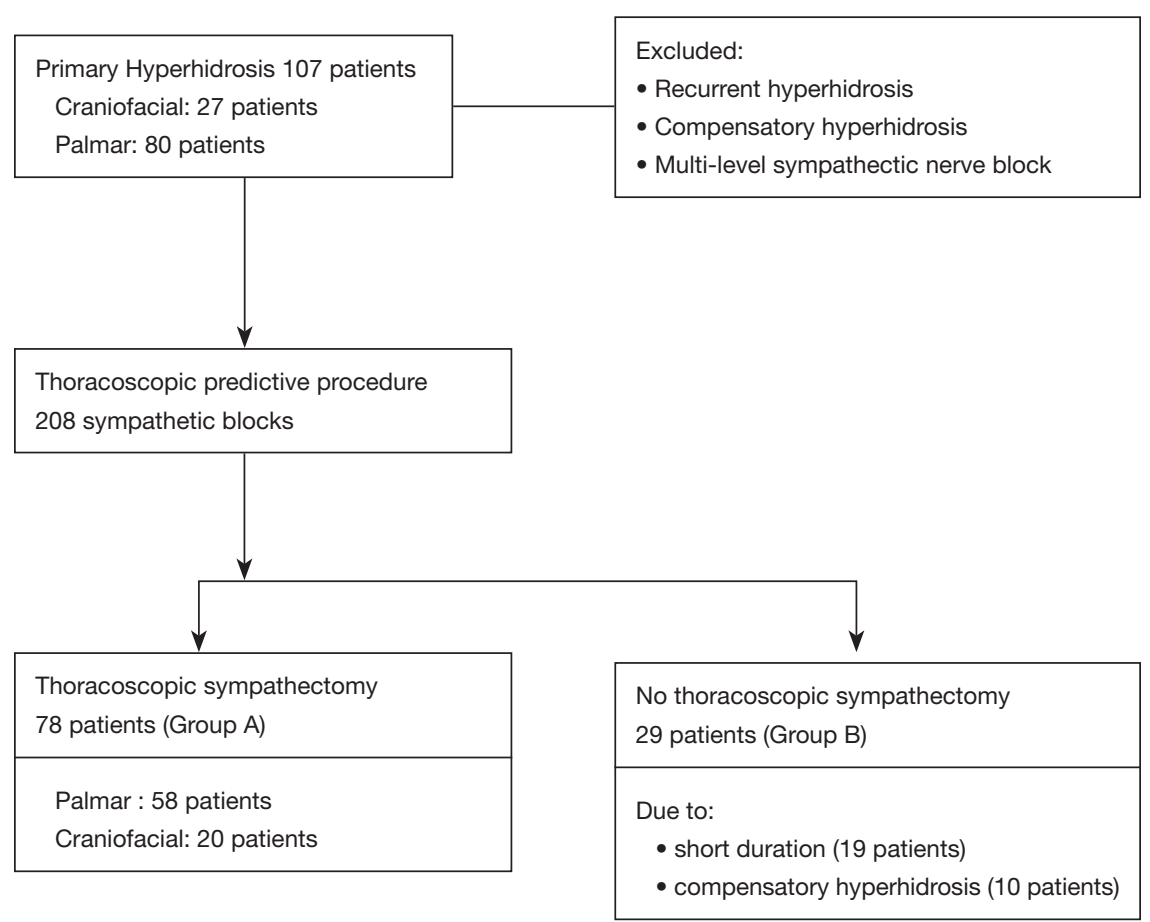

Figure 1 Thoracoscopic predictive procedure and sympathectomy for primary hyperhidrosis
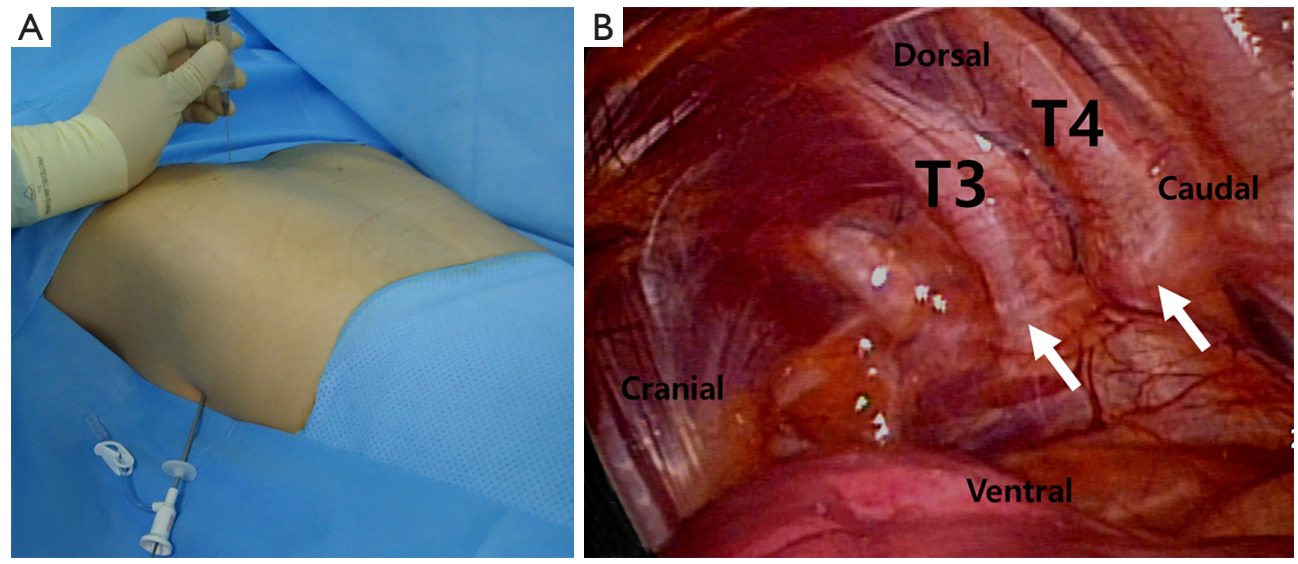

Figure 2 Thoracoscopic sympathetic block of left sympathetic nerve with the patient placed in prone position. (A) Operative field; (B) intraoperative findings; T3, third rib; T4, fourth rib; Arrows, sympathetic chains.

interviewed about the effect of $\mathrm{PH}$, complications and occurrence of compensatory sweating. The patients decided whether to proceed with sympathectomy. One week after sympathectomy, their satisfaction was reassessed. In interviews, compensatory sweating was graded, as one of the followings: absent, mild, moderate and severe. In our data analysis, 'absent' and 'mild' were not classified as $\mathrm{CH}$, while 'moderate' and 'severe' were classified as $\mathrm{CH}$.

\section{Statistical analysis}

We retrospectively analyzed the perioperative data of patients who underwent the predictive procedure either followed, or not followed, by sympathectomy. Continuous variables are presented as means with standard deviations, and categorical variables are presented as counts and percentages. Continuous variables were analyzed using the independent- 
Table 1 Perioperative characteristics of all patients who underwent predictive procedure

\begin{tabular}{lc}
\hline Characteristic & Value \\
\hline Male:female & $66(61.7): 41(38.3)$ \\
Age, years & $32.3 \pm 13.9$ \\
BMl, kg/m ${ }^{2}$ & $23.5 \pm 3.43$ \\
Hyperhidrosis site & \\
Craniofacial & $27(25.2)$ \\
Palmar & $80(74.8)$ \\
Sympathetic level of target & \\
T3 & $106(99.1)$ \\
T4 & $1(0.9)$ \\
Procedure time of PP, minutes & $32.6 \pm 9.4$ \\
Relief of primary hyperhidrosis & $107(100.0)$ \\
Effective duration of the PP, hours & $28.1 \pm 41.5$ \\
Compensatory hyperhidrosis & $32(29.9)$ \\
Pneumothorax & $5(4.8)$ \\
Temporary ptosis & $9(8.4)$ \\
\hline
\end{tabular}

Values are number $(\%)$ or mean \pm SD. BMI, body mass index; PP, predictive procedure.

sample t-test and categorical variables were analyzed using the chi-square or Fisher exact test for comparisons between groups. Statistical significance was defined by $\mathrm{P}$ values $<0.05$. All statistical analyses were performed using IBM SPSS ver. 26.0 (IBM Corp., Armonk, NY, USA),

\section{Results}

\section{Predictive procedure}

Of 107 patients, $66(61.7 \%)$ were male and 41 (38.3\%) were female (Table 1). The mean age of patients was 32.3 (from 14 to 67 ) years. Eighty patients (74.8\%) had palmar hyperhidrosis and 27 patients $(25.2 \%)$ had craniofacial symptom. Thoracoscopic sympathetic blocks were done for 106 patients at T3 level and 1 patient at T4 level. The mean procedure time of the predictive procedure was 32.6 minutes. $\mathrm{PH}$ was relieved in all patients by the procedure without severe complications requiring chest tube. The mean effective duration of nerve block was 28.1 (range 6-168) hours. CH occurred in 32 patients (29.9\%) and did not occur in 52 patients (48.6\%). Twenty-three patients $(21.5 \%)$ were unsure of the presence of sweating. Pneumothorax occurred in 5 patients (4.8\%). All the five patients did not require chest tube insertion and were discharged postoperatively after one day. Temporary ptosis occurred in 9 patients (8.4\%) and they all improved within one day.

\section{Operation decision}

After the predictive procedure, 78 patients (72.9\%) decided to have sympathectomy (group A). Twenty-nine patients $(27.1 \%)$ of group B chose not to proceed due to short duration of sympathetic block effect and CH (Figure 1). By comparing group A with group B, we evaluated the factors contributing to patients' decision making for proceeding with sympathectomy (Table 2). Characteristics including sex, age and hyperhidrosis site were not significantly different between the two groups. Group B tended to have higher average body mass index (BMI) $(24.5$ versus $23.2, \mathrm{P}=0.107)$ and $\mathrm{CH}$ rate $(37.9 \%$ versus $26.9 \%, \mathrm{P}=0.269)$ compared to group A. Twenty-one patients of group A and 11 of group $\mathrm{B}$ were experienced $\mathrm{CH}$ after nerve block. However, the differences were not significant. The longer effective duration of sympathetic block was a statistically significant factor for deciding to have surgery (33.5 versus 13.9 hours, $\mathrm{P}=0.001$ ).

\section{Sympathectomy}

All 78 patients who underwent sympathectomy (group A) had positive effects on $\mathrm{PH}$ and of these $76.9 \%$ (60 patients) experienced $\mathrm{CH}$ after sympathetic surgery. In 20 patients who had $\mathrm{CH}$ after both predictive procedure and sympathectomy, 4 experienced worse compensatory sweating after sympathectomy than nerve block, and the others reported same degree of compensatory sweating after both procedures. Six patients (7.7\%) had mild pneumothorax on chest $\mathrm{X}$ ray which was resolved spontaneously. One patient $(1.3 \%)$ had temporary subcutaneous emphysema.

In 78 patients of group $\mathrm{A}, \mathrm{CH}$ was considered a positive sign after predictive procedure and sympathectomy, respectively (Table 3). Based on Table 3, the validity of our predictive procedure is summarized in Table 4. During the study period, our predictive procedure had $94.4 \%$ specificity and $33.3 \%$ sensitivity for prediction of $\mathrm{CH}$ after sympathectomy. $95.2 \%$ of positive predictive rate and $29.8 \%$ negative predictive rate of the predictive procedure were founded in this study. By dividing the group A into two groups 
Table 2 Perioperative characteristics of patients based on choice with regard to sympathectomy

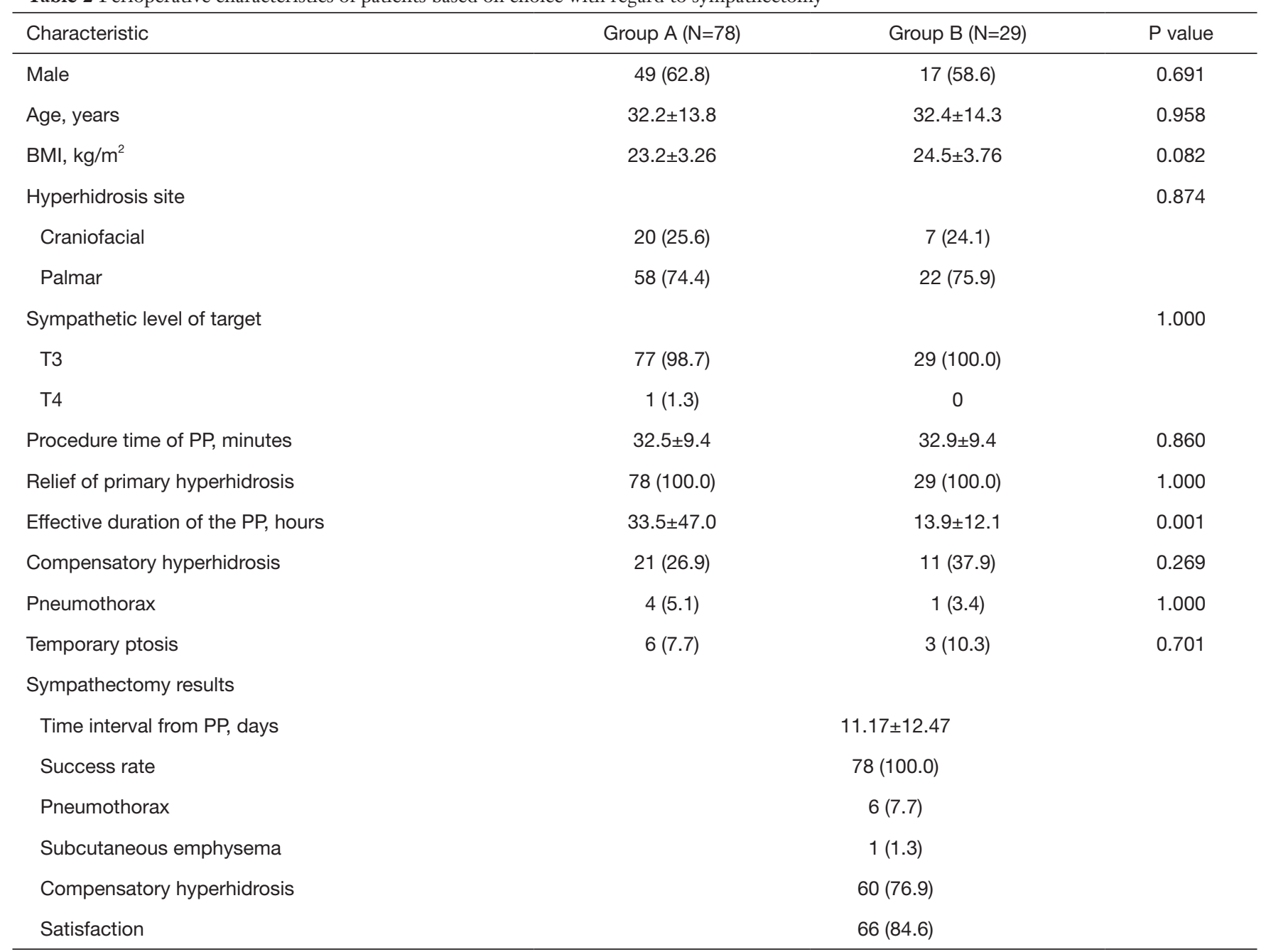

Values are number (\%) or mean \pm SD. Group A: Patients who underwent sympathectomy after predictive procedure. Group B: Patients who did not have sympathectomy after predictive procedure. BM, body mass index; PP, predictive procedure; N, number.

according to primary symptom site, we analyzed differences in the $\mathrm{CH}$ and satisfaction rate after sympathectomy (Table 5). The satisfaction rate was higher for the palmar hyperhidrosis group than the craniofacial hyperhidrosis group $(91.4 \%$ versus $65.0 \%, \mathrm{P}=0.010$ ). However, the $\mathrm{CH}$ rates after sympathectomy showed no significant difference in the two groups. Just as the results of $\mathrm{CH}$ rate after sympathectomy (Table 5), there was no statistically significant difference in $\mathrm{CH}$ rate after predictive procedure between palmar and craniofacial group in this study (Table 6).

\section{Discussion}

Postsympathectomy $\mathrm{CH}$ is an irreversible complication.
There are several reports on reversibility of thoracic sympathetic surgery. Kara and colleagues (18) performed bilateral thoracic sympathetic clipping in 183 patients with $\mathrm{PH}$ and removed the clips in 8 patients who had disabling $\mathrm{CH}$ after clipping. They showed that only 2 patients (25\%) had favorable satisfaction results after clip removal.

Rantanen and Telaranta (19) reviewed the records of 150 patients who underwent sympathetic nerve transplantation for severe side effects of sympathectomy for PH. Only 19 patients responded to the follow-up questionnaire. Among them, 7 patients (36.8\%) were found to have had significantly reduced compensatory sweating after nerve reconstruction. Miller and colleagues (14) reported a temporary thoracoscopic sympathetic block as a predictive 
Table 3 Compensatory hyperhidrosis after both predictive procedure and sympathectomy in group A

\begin{tabular}{|c|c|c|}
\hline Occurrence of $\mathrm{CH}$ (Total 78 patients) & \multicolumn{2}{|c|}{$\mathrm{CH}$ after $\mathrm{PP}$} \\
\hline \multirow[t]{2}{*}{ Positive } & Total 20 & Total 40 \\
\hline & Palmar 12 & Palmar 32 \\
\hline \multirow[t]{3}{*}{ Negative } & Total 1 & Total 17 \\
\hline & Palmar 1 & Palmar 13 \\
\hline & Craniofacial 0 & Craniofacial 4 \\
\hline
\end{tabular}

$\mathrm{CH}$, compensatory hyperhidrosis; PP, predictive procedure.

Table 4 Validity of predictive procedure for prediction of compensatory hyperhidrosis after sympathectomy

\begin{tabular}{lc}
\hline Validity & Value (\%) \\
\hline Sensitivity & 33.3 \\
Specificity & 94.4 \\
Positive predictive rate & 95.2 \\
Negative predictive rate & 29.8 \\
\hline
\end{tabular}

procedure. They used a local anesthetic agent for reversing sympathetic block. All patients had temporary relief of hyperhidrosis and three patients had temporary $\mathrm{CH}$ after the sympathetic block in their study. Our institution has also elected to use the predictive procedure from July 2009 to help patients decide whether to proceed with sympathectomy.

We have attempted the use of several local anesthetic agents for sympathetic nerve block to find good local anesthetics which have proper effective duration. Too short a duration of sympathetic block could make it difficult for patients to experience dryness and compensatory sweating. Alternatively too a long duration becomes inconvenient for patients awaiting recovery of symptoms [for example, using botulinum toxin A (20)]. In March 2017, we established our protocol for the local anesthetics, by combining ropivacaine, epinephrine and dexamethasone. We adjusted the dose of ropivacaine $(37.5 \mathrm{mg})$ with reference to Kuthiala's report (21). The steroid agent (dexamethasone) was used for prolonging the duration of nerve block. And epinephrine was for preventing peripheral absorption of anesthetic agent (ropivacaine). We have now reviewed the outcomes of the predictive procedures in our institution to analyze recent experience using the protocol.

All our predictive procedures and sympathectomies were done effectively and safely. Even cases with complications were not required the thoracostomy tube drainage, and most patients were discharged on the operative day. Indeed, all other complications including ptosis were temporary.

However, $\mathrm{CH}$ rate after the predictive procedure was much lower than that seen with sympathectomies $(29.9 \%$ versus $76.9 \%$ ). The short duration of the sympathetic block effect might have not allowed the compensatory reaction to occur in patients. The effective duration was significantly shorter in patients who refused to proceed the sympathectomy emphasizing the importance of getting the duration right. As we used same dose of ropivacaine for all patients regardless of their BMI, the patients of group $\mathrm{B}$ who had have higher average BMI might have shorter duration of nerve block effect. Compared with our early experience $(15,16)$ the average effective duration of the predictive procedure in this study was not longer. This means that we did not improve the block duration time by defining a new protocol for the local anesthetics.

In a study by Miller and colleagues (14), temporary relief of hyperhidrosis happened to all 25 patients. The occurrence rate of $\mathrm{CH}$ after predictive procedure was $12 \%$ (3 patients) in their study. One patient (4\%) with severe $\mathrm{CH}$ after predictive procedure decided not to proceed with the sympathectomy in Miller's report (14). All but one (24 patients) elected to proceed with the planned sympathectomy. And two $(8.33 \%)$ had $\mathrm{CH}$ after sympathectomy. In our study, the total 107 patients had $29.9 \%$ of $\mathrm{CH}$ rate after nerve block and group A had $76.9 \%$ 
Table 5 Compensatory hyperhidrosis and satisfaction rates after sympathectomy based on primary symptom site in group A

\begin{tabular}{lccc}
\hline Site of primary symptom & Palmar hyperhidrosis $(\mathrm{N}=58)$ & Craniofacial hyperhidrosis $(\mathrm{N}=20)$ & $\mathrm{P}$ value \\
\hline $\mathrm{CH}$ after sympathectomy & $44(75.9)$ & $16(80.0)$ & 1.000 \\
Satisfaction & $53(91.4)$ & $13(65.0)$ & 0.010 \\
\hline
\end{tabular}

Values are number (\%). N, number; $\mathrm{CH}$, compensatory hyperhidrosis.

Table 6 Compensatory hyperhidrosis rates after predictive procedure based on primary symptom site in all patients

\begin{tabular}{|c|c|c|c|}
\hline Site of primary symptom & Palmar hyperhidrosis & Craniofacial hyperhidrosis & $P$ value \\
\hline $\mathrm{CH}$ after $\mathrm{PP}$ & $21(26.3)$ & $11(40.7)$ & 0.155 \\
\hline Group A N=78 & 58 & 20 & \\
\hline $\mathrm{CH}$ after $\mathrm{PP}$ & $13(22.4)$ & $8(40.0)$ & 0.126 \\
\hline $\mathrm{CH}$ after $\mathrm{PP}$ & $8(36.4)$ & $3(42.9)$ & 1.000 \\
\hline
\end{tabular}

Values are number (\%). N, number; $\mathrm{CH}$, compensatory hyperhidrosis; PP, predictive procedure.

of $\mathrm{CH}$ rate after sympathectomy.

We had just a week of mandatory follow up period after both predictive procedure and sympathectomy. Even though longer outpatient clinic follow-up period is judged to be important to assess compensatory sweating of patients, the outpatient visits are voluntarily left to the patients at our department. We were somewhat convinced of that the duration of the outpatient follow up did not significantly affect the patient's satisfaction.

In terms of validity, our predictive procedure had both high specificity (94.4\%) and high positive predictive rate (95.2\%) for CH. So, the patients who present with $\mathrm{CH}$ after the predictive procedure might need to be informed of the strong chance of $\mathrm{CH}$ occurrence after sympathectomy. We believe that the too low $\mathrm{CH}$ rate after predictive procedures led to the low sensitivity value of the procedure. If the average effect time of the procedure was longer, the sensitivity might have been higher by elevating the $\mathrm{CH}$ rate after predictive procedure.

Araujo and colleagues (22) reported that higher BMI is related to patients' dissatisfaction after thoracoscopic sympathectomy. That observation might account for the relationship between higher BMI and higher tendency of patient refusal for sympathectomy in our study. Even though $\mathrm{CH}$ rate of sympathectomy was higher than that of the predictive procedure (76.9\% versus $26.9 \%$ ) in group A (Table 2), the satisfaction rate was $84.6 \%$. The cause of high satisfaction rate may have been influenced by that some have already experienced $\mathrm{CH}$ from predictive procedure, and the others had heard the detailed preoperative explanation of $\mathrm{CH}$ after sympathectomy.

Regardless of higher success rate of T2 sympathectomy for craniofacial $\mathrm{PH}$, we tend to be reluctant to practice $\mathrm{T} 2$ sympathectomy for craniofacial cases due to complications including severe $\mathrm{CH}$ related to high level sympathectomy. As we performed mostly T3 sympathectomy in both craniofacial and palmar hyperhidrosis during our study period, we expected lower satisfaction rate in craniofacial group (Table 5).

This study has several limitations, including the retrospective design, the short period of follow-up, and lack of comparing of these results with our early experiences.

\section{Conclusions}

The predictive procedure was safely performed on all patients. Sympathetic nerve block before sympathectomy gave patients an opportunity to experience the effect of sympathectomy on $\mathrm{PH}$ and occurrence of $\mathrm{CH}$. In addition, consecutive sympathectomy provided high satisfaction for our patients. However, the duration of sympathetic nerve block was too short. As one of the main factors for patients in making a decision to proceed with the surgery was nerve block effect duration, longer duration would help patients 
to decide whether to undergo the operation. Finally, a randomized, prospective, comparative study with long-term follow-up is necessary to confirm the clinical advantages of the predictive procedure for $\mathrm{CH}$.

\section{Acknowledgments}

This paper was edited by the professional English editors at HARRISCO, Scientific English Research Paper Editing Service.

Funding: None.

\section{Footnote}

Reporting Checklist: The authors have completed the STROBE reporting checklist. Available at http://dx.doi. org/10.21037/jtd-21-229

Data Sharing Statement: Available at http://dx.doi. org/10.21037/jtd-21-229

Peer Review File: Available at http://dx.doi.org/10.21037/jtd21-229

Conflicts of Interest: All authors have completed the ICMJE uniform disclosure form (available at http://dx.doi. org/10.21037/jtd-21-229). The authors have no conflicts of interest to declare.

Ethical Statement: The authors are accountable for all aspects of the work in ensuring that questions related to the accuracy or integrity of any part of the work are appropriately investigated and resolved. The study was conducted in accordance with the Declaration of Helsinki (as revised in 2013). The study was approved by the Institutional Review Board (IRB) of our medical institution (IRB approval number: OC20RASI0095). Informed consent was waived due to the retrospective nature of the current study.

Open Access Statement: This is an Open Access article distributed in accordance with the Creative Commons Attribution-NonCommercial-NoDerivs 4.0 International License (CC BY-NC-ND 4.0), which permits the noncommercial replication and distribution of the article with the strict proviso that no changes or edits are made and the original work is properly cited (including links to both the formal publication through the relevant DOI and the license).
See: https://creativecommons.org/licenses/by-nc-nd/4.0/.

\section{References}

1. Tetteh HA, Groth SS, Kast T, et al. Primary palmoplantar hyperhidrosis and thoracoscopic sympathectomy: a new objective assessment method. Ann Thorac Surg 2009;87:267-74.

2. Baumgartner FJ, Bertin S, Konecny J. Superiority of thoracoscopic sympathectomy over medical management for the palmoplantar subset of severe hyperhidrosis. Ann Vasc Surg 2009;23:1-7.

3. Rodriguez PM, Freixinet JL, Hussein M, et al. Side effects, complications and outcome of thoracoscopic sympathectomy for palmar and axillary hyperhidrosis in 406 patients. Eur J Cardiothorac Surg 2008;34:514-9.

4. Dumont P, Denoyer A, Robin P. Long-term results of thoracoscopic sympathectomy for hyperhidrosis. Ann Thorac Surg 2004;78:1801-7.

5. Girish G, D'Souza RE, D'Souza P, et al. Role of surgical thoracic sympathetic interruption in treatment of facial blushing: a systematic review. Postgrad Med 2017;129:267-75.

6. Fukuda JM, Varella AYM, Teivelis MP, et al. VideoAssisted Thoracoscopic Sympathectomy for Facial Hyperhidrosis: The Influence of the Main Site of Complaint. Ann Vasc Surg 2018;46:337-44.

7. Weksler B, Blaine G, Souza ZB, et al. Transection of more than one sympathetic chain ganglion for hyperhidrosis increases the severity of compensatory hyperhidrosis and decreases patient satisfaction. J Surg Res 2009;156:110-5.

8. Hwang JJ, Kim DH, Hong YJ, et al. A comparison between two types of limited sympathetic surgery for palmar hyperhidrosis. Surg Today 2013;43:397-402.

9. Lee SS, Lee YU, Lee JH, et al. Comparison of the Long-Term Results of R3 and R4 Sympathicotomy for Palmar Hyperhidrosis. Korean J Thorac Cardiovasc Surg 2017;50:197-201.

10. Joo S, Lee GD, Haam S, et al. Comparisons of the clinical outcomes of thoracoscopic sympathetic surgery for palmar hyperhidrosis: $\mathrm{R} 4$ sympathicotomy versus $\mathrm{R} 4$ sympathetic clipping versus R3 sympathetic clipping. J Thorac Dis 2016;8:934-41.

11. Licht PB, Pilegaard HK. Severity of compensatory sweating after thoracoscopic sympathectomy. Ann Thorac Surg 2004;78:427-31.

12. Sugimura H, Spratt EH, Compeau CG, et al. Thoracoscopic sympathetic clipping for hyperhidrosis: long-term results and reversibility. J Thorac Cardiovasc 
Surg 2009;137:1370-6.

13. Haam SJ, Park SY, Paik HC, et al. Sympathetic nerve reconstruction for compensatory hyperhidrosis after sympathetic surgery for primary hyperhidrosis. J Korean Med Sci 2010;25:597-601.

14. Miller DL, Force SD. Temporary thoracoscopic sympathetic block for hyperhidrosis. Ann Thorac Surg 2008;85:1211-4.

15. Jeong JY, Park HJ, Park JK, et al. Predictive procedure for compensatory hyperhidrosis before sympathectomy: preliminary findings. Thorac Cardiovasc Surg 2014;62:434-8.

16. Jeong JY, Park SS, Sim SB, et al. Prediction of compensatory hyperhidrosis with botulinum toxin A and local anesthetic. Clin Auton Res 2015;25:201-5.

17. Solish N, Bertucci V, Dansereau A, et al. A comprehensive approach to the recognition, diagnosis, and severity-based treatment of focal hyperhidrosis: recommendations of the Canadian Hyperhidrosis Advisory Committee. Dermatol

Cite this article as: Lee J, Jeong JY, Suh JH, Park CB, Kwoun H, Park SS. Thoracoscopic sympathetic block to predict compensatory hyperhidrosis in primary hyperhidrosis. J Thorac Dis 2021;13(6):3509-3517. doi: 10.21037/jtd-21-229
Surg 2007;33:908-23

18. Kara M, Kose S, Ozkan B, et al. Does clip removal help for compensatory hyperhidrosis complicating thoracic sympathetic clipping? Clin Auton Res 2019;29:353-5.

19. Rantanen T, Telaranta T. Long-Term Effect of Endoscopic Sympathetic Nerve Reconstruction for Side Effects after Endoscopic Sympathectomy. Thorac Cardiovasc Surg 2017;65:484-90.

20. Bhidayasiri R, Truong DD. Evidence for effectiveness of botulinum toxin for hyperhidrosis. J Neural Transm (Vienna) 2008;115:641-5.

21. Kuthiala G, Chaudhary G. Ropivacaine: A review of its pharmacology and clinical use. Indian J Anaesth 2011;55:104-10.

22. Araujo CA, Azevedo IM, Ferreira MA, et al. Compensatory sweating after thoracoscopic sympathectomy: characteristics, prevalence and influence on patient satisfaction. J Bras Pneumol 2009;35:213-20. 